\title{
FUZZY QUERY DATABASE UNTUK SISTEM PENDUKUNG KEPUTUSAN YANG CERDAS
}

\author{
Poningsih, Jalalludin \\ Program Studi Manajemen Informatika, AMIK Tunas Bangsa Pematangsiantar \\ Jln. Jenderal Sudirman Blok A No. 1,2,3 Pematangsiantar \\ poningsih@amiktunasbangsa.ac.id, jalalludin@amiktunasbangsa.ac.id
}

\begin{abstract}
The process of education and teaching is one of the acts of Tri Dharma College. The success of the learning process can not be separated from the role of a lecturer. Quality of faculty plays an important role in a college that wants to achieve the goal of teaching and learning processes that produce graduates (output) quality. Lecturer rated quality if it has the value of a good performance, which is reviewed from several aspects. This paper proposes an analysis based on the evaluation of faculty performance feedback using fuzzy query the database for intelligent decision support system. The value of sangtlah diverse faculty performance, so as to the criteria of each lecturer is still ambiguous and still need to be clarified. Here will be determined three criteria of assessment of faculty performance is lacking, just and good. Of the three criteria are later obtained a recommendation to make a decision. Model rules obtained is the value of students and professors taken the maximum value, then rulenya obtained from students and professors taken minimum value, in order to obtain the value of the performance of lecturers as well as the criteria. Then the value of this performance, it can be used by institutions as advice on making a decision relating to a lecturer.
\end{abstract}

Keywords: Fuzzy logic, Fuzzy query the database, faculty performance, decision support systems.

\begin{abstract}
ABSTRAK
Proses pendidikan dan pengajaran adalah salah satu pelaksanaan Tri Dharma Perguruan Tinggi. Keberhasilan proses belajar mengajar tidak terlepas dari peran seorang dosen. Kualitas dosen memegang peranan penting di suatu perguruan tinggi yang ingin mencapai tujuan proses belajar mengajar yaitu menghasilkan lulusan (output) yang berkualitas. Dosen dinilai berkualitas apabila memiliki nilai kinerja yang baik, yang ditinjau dari beberapa aspek. Paper ini mengusulkan sebuah analisis kinerja dosen berdasarkan evaluasi umpan balik menggunakan metode fuzzy query database untuk sistem pendukung keputusan yang cerdas. Nilai dari kinerja dosen sangtlah beragam, sehingga untuk kriteria dari masing-masing dosen masih bersifat ambigu dan masih perlu diperjelas lagi. Disini akan ditentukan 3 kriteria dari penilaian kinerja dosen yaitu kurang, cukup dan baik. Dari ketiga kriteria tersebut nantinya akan diperoleh sebuah rekomendasi untuk menghasilkan sebuah keputusan. Model aturan
\end{abstract}


yang diperoleh adalah nilai dari mahasiswa dan dosen yang diambil nilai maksimalnya, kemudian rulenya diperoleh dari mahasiswa dan dosen yang diambil nilai minimalnya, sehingga diperoleh nilai kinerja dosen serta kriterianya. Kemudian dari nilai kinerja ini, dapat digunakan oleh institusi sebagai rekomendasi untuk pengambilan sebuah keputusan yang berhubungan dengan seorang dosen.

Kata kunci: logika Fuzzy, Fuzzy query database, kinerja dosen, sistem pendukung keputusan.

\section{PENDAHULUAN}

Salah satu bentuk pelaksanaan Tri Dharma Perguruan Tinggi adalah pendidikan dan pengajaran. Dalam hal ini keberhasilan proses pendidikan dan pengajaran di suatu Perguruan tinggi sangatlah bergantung pada performa dari seorang dosen itu sendiri. [1]Pada proses menentukan penilaian yang layak terhadap kinerja dosen tentunya kita harus memiliki kriteria-kriteria dosen yang layak supaya memberikan penilaian sesuai dengan ketentuan yang telah ditetapkan. Kriteriakriteria tersebut memiliki nilai yang tidak pasti. Sedangkan data yang ada pada database institusi adalah data yang bernilai pasti. Oleh karena itu, untuk menangani kriteria-kriteria yang memiliki nilai yang tidak pasti tersebut kita dapat menggunakan logika fuzzy. Pada paper ini, sistem yang dibangun menggunakan model DBMS dan query yang berbasis fuzzy, karena model DBMS konvensional, non fuzzy, kurang dapat memenuhi kebutuhan sistem informasi seperti ini. DBMS dan query model Tahani dapat dengan tepat memetakan suatu ruang input (fuzzy query) ke output sebagai informasi hasil query. [2]Kualitas dosen memegang peranan penting di suatu perguruan tinggi yang ingin mencapai tujuan proses belajar mengajar yaitu menghasilkan lulusan (output) yang berkualitas. Dosen dinilai berkualitas apabila memiliki nilai kinerja yang baik, yang ditinjau dari beberapa aspek. [7]Untuk itu sangat perlu dilakukan sebuah analisis untuk mengetahui nilai kinerja dari seorang dosen khususnya di AMIK Tunas Bangsa Pematangsiantar yang nantinya akan dijadikan sebagai masukan bagi bagian akademik AMIK Tunas Bangsa Pematangsiantar. [6]Sebelumnya AMIK Tunas Bangsa telah menerapkan evaluasi terhadap kinerja dosen dengan menggunakan alat ukur yang dikenal dengan nama Evaluasi Umpan Balik (EUB). Salah satu variabel yang digunakan untuk menghitung nilai kinerja dosen adalah penilaian dari mahasiswa yang mengambil matakuliah yang diampu oleh dosen yang bersangkutan. Penilaian oleh mahasiswa dilakukan melalui pengisian kuesioner. Kendati hal ini sudah dilakukan, namun hasil yang dicapai kurang maksimal. Mengingat hasil dari evaluasi umpan balik yang selama ini sudah dilakukan belum menghasilkan nilai akhir dari kinerja dosen. Ada 10 pertanyaan yang diberikan dalam kuesioner, yaitu: kemampuan pengajar dalam merangsang dan menumbuhkan minat terhadap matakuliah, kepedulian pengajar yang ditujukan pada minat terhadap matakuliah, kemampuan berkomunikasi dengan cara yang bisa dimengerti, kesempatan untuk mengajukan pertanyaan tentang materi kuliah, 
pengorganisasian materi perkuliahan dari matakuliah, cara penyampaian materi perkuliahan, rangsangan untuk berpikir kritis dan analitis, relevansi tugas yang diberikan terhadap matakuliah, kesediaan pengajar untuk konsultasi dengan mahasiswa, pengembalian kertas ujian dan tugas. Setiap pertanyaan memiliki nilai mulai dari 1(Kurang Sekali), 2(Kurang), 3(Cukup), 4(Baik), 5(Baik Sekali). Penilaian dari mahasiswa ini bersifat kualitatif. Selain penilaian mahasiswa, penilaian kinerja dosen juga dipengaruhi oleh kehadiran dosen yang bersifat kuantitatif.

Berdasarkan penjelasan di atas, maka penulis membuat suatu gagasan untuk membangun suatu model yang digunakan untuk menentukan nilai kriteria dari seorang dosen. Dan nantinya sistem tersebut akan dikembangkan sampai menghasilkan sebuah rekomendasi yang dapat dijadikan sebagai acuan untuk sebuah keputusan terhadap seorang dosen di suatu Institusi khususnya di AMIK Tunas Bangsa. Penelitian ini diharapkan dapat memberikan kontribusi bagi ilmu pengetahuan di bidang ilmu komputer, khususnya bagi perguruan tinggi swasta Akademi Manajemen Informatika Komputer (AMIK) Tunas Bangsa Pematangsiantar.

\section{METODE PENELITIAN}

1. Lokasi Penelitian

Penelitian dilakukan di AMIK Tunas Bangsa Pematangsiantar, yang beralamat di Jl. Jendral Sudirman Blok A No. 1/2/3 Pematangsinatar.

2. Populasi dan Sampel

Populasi pada penelitian ini adalah mahasiswa dan dosen

3. Identifkasi kebutuhan, pengumpulan data dengan kegiatan menyebarkan questioner yang diisioleh dosen dan mahasiswa, dan studi kepustakaan.

\section{HASIL DAN PEMBAHASAN}

\subsection{Kuisioner data penilaian mahasiswa}

Kuesioner yang diisi oleh mahasiswa (variabel x) terdiri dari 10 pertanyaan, dengan bobot nilai minimal 1 dan maksimal 5 dengan fungsi keanggotaan kurang sekali, kurang, cukup, baik, dan baik sekali. Dengan kategori nilai:

\begin{tabular}{|l|l|}
\hline Nilai & Kategori \\
\hline $0-10$ & Kurang Sekali \\
\hline $5-20$ & Kurang \\
\hline $15-30$ & Cukup \\
\hline $25-40$ & Baik \\
\hline $35-50$ & Baik Sekali \\
\hline
\end{tabular}

\subsection{Fuzzifikasi Kuesioner Data Penilaian Mahasiswa}

Setelah menentukan nilai tegas (crisp) dari kuesioner yang diperoleh dari data mahasiswa, maka selanjutnya dilakukan proses fuzzifikasi dari nilai-nilai tersebut. 


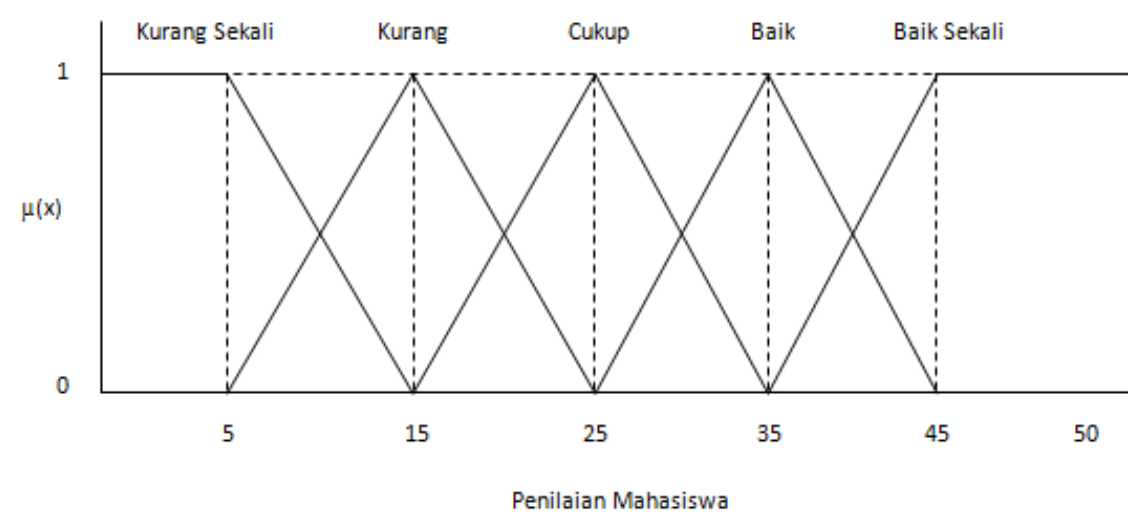

\subsection{Menentukan Derajat Keanggotaan Data Penilaian Mahasiswa $\left(\mu_{\mathrm{x}}\right)$}

Setelah proses fuzzifikasi, selanjutnya ditentukan derajat keanggotaan mahasiswa yaitu derajat keanggotaan kurang sekali $\left(\mu_{\mathrm{K} s}\right)$, derajat keanggotaan kurang $\left(\mu_{\mathrm{K}}\right)$, derajat keanggotaan cukup $(\mu \mathrm{c})$, derajat keanggotaan baik $\left(\mu_{\mathrm{B}}\right)$, derajat keanggotaan baik sekali $\left(\mu_{\mathrm{BS}}\right)$ dengan ketentuan rumus:

$$
\begin{aligned}
& \mu_{\mathrm{KS}}= \begin{cases}1 & ; \mathrm{x} \leq 5 \\
\frac{(15-\mathrm{x})}{(15-5)} & ; 5 \leq \mathrm{x} \leq 15 \\
0 & ; \mathrm{x} \geq 15\end{cases} \\
& \mu_{\mathrm{K}}= \begin{cases}0 & ; \mathrm{x} \leq 15 \text { atau } \mathrm{x} \geq 25 \\
\frac{(\mathrm{x}-5)}{(15-5)} & ; 5 \leq \mathrm{x} \leq 15 \\
\frac{(25-\mathrm{x})}{(25-15)} & ; 15 \leq \mathrm{x} \leq 25\end{cases} \\
& \mu_{\mathrm{C}}= \begin{cases}0 & ; \mathrm{x} \leq 15 \text { atau } \mathrm{x} \geq 35 \\
\frac{(\mathrm{x}-15)}{(25-15)} & ; 15 \leq \mathrm{x} \leq 25 \\
\frac{(35-\mathrm{x})}{(35-25)} & ; 25 \leq \mathrm{x} \leq 35\end{cases}
\end{aligned}
$$




$$
\begin{aligned}
& \mu_{\mathrm{B}}= \begin{cases}0 & ; \mathrm{x} \leq 25 \text { atau } x \geq 45 \\
\frac{(\mathrm{x}-25)}{(35-25)} & ; 25 \leq \mathrm{x} \leq 35 \\
\frac{(45-\mathrm{x})}{(45-35)} & ; 35 \leq \mathrm{x} \leq 45\end{cases} \\
& \mu_{\mathrm{BS}}= \begin{cases}0 & ; \mathrm{x} \leq 35 \\
(\mathrm{x}-35) & ; 35 \leq \mathrm{x} \leq 45 \\
(45-35) & ; \mathrm{x} \geq 45 \\
1 & \end{cases}
\end{aligned}
$$

\section{Keterangan:}

KS = Kurang Sekali

$\mathrm{K}=$ Kurang

$\mathrm{C}=$ Cukup

$\mathrm{B}=$ Baik

BS = Baik Sekali

Semesta pembicaraan $\left[\begin{array}{ll}0 & 50\end{array}\right]$.

\subsection{Domain kuesioner data penilaian mahasiswa}

Domain data kuesioner mahasiswa adalah:

$\begin{array}{ll}\text { Kurang Sekali } & :\left[\begin{array}{ll}0 & 15\end{array}\right] \\ \text { Kurang } & :\left[\begin{array}{ll}5 & 25\end{array}\right] \\ \text { Cukup } & :\left[\begin{array}{ll}15 & 35\end{array}\right] \\ \text { Baik } & :\left[\begin{array}{ll}25 & 45\end{array}\right] \\ \text { Baik Sekali } & :\left[\begin{array}{ll}35 & 50\end{array}\right]\end{array}$

\subsection{Kuesioner Data Penilaian Dosen}

Kuesioner yang diisi oleh dosen (variabel y) terdiri dari 10 pertanyaan, dengan bobot nilai minimal 1 dan maksimal 5 dengan fungsi keanggotaan cukup, baik, dan baik sekali. Dengan kategori nilai:

\begin{tabular}{|l|l|}
\hline Nilai & Kategori \\
\hline $0-25$ & Cukup \\
\hline $20-40$ & Baik \\
\hline $35-50$ & Baik Sekali \\
\hline
\end{tabular}




\subsection{Fuzzifikasi Kuesioner Data Penilaian Dosen}

Setelah menentukan nilai tegas (crisp) dari kuesioner yang diperoleh dari data dosen, maka selanjutnya dilakukan proses fuzzifikasi dari nilai-nilai tersebut.

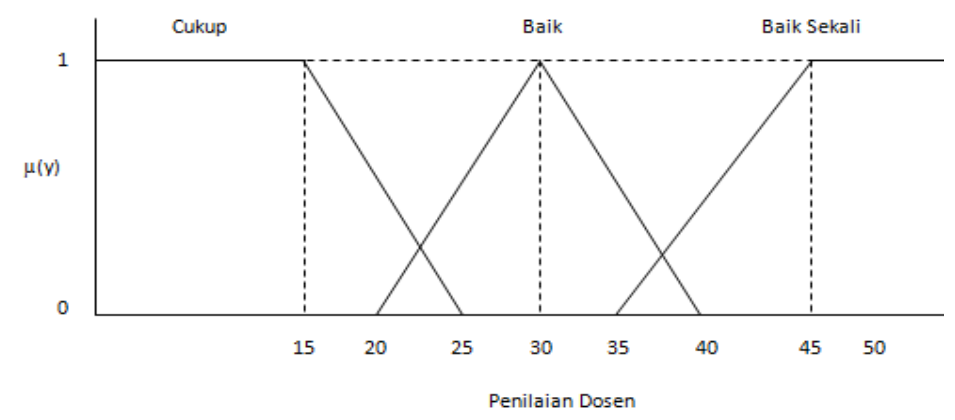

\subsection{Menentukan Derajat Keanggotaan Data Penilaian Dosen $\left(\mu_{y}\right)$}

Setelah proses fuzzifikasi, selanjutnya ditentukan derajat keanggotaan dosen yaitu derajat keanggotaan cukup $\left(\mu_{\mathrm{c}}\right)$, derajat keanggotaan baik $\left(\mu_{\mathrm{B}}\right)$, derajat keanggotaan baik sekali $\left(\mu_{\mathrm{BS}}\right)$ dengan ketentuan rumus:

$$
\begin{aligned}
& \mu_{C}= \begin{cases}1 ; x \leq 15 & (15-x) \\
(25-15) & ; 15 \leq x \leq 25 \\
0 & ; x \geq 25\end{cases} \\
& \mu_{B}= \begin{cases}0 & ; x \leq 20 \text { atau } x \geq 40 \\
\frac{(x-20)}{(30-20)} & ; 20 \leq x \leq 30 \\
\frac{(40-x)}{(40-30)} & ; 30 \leq x \leq 40\end{cases} \\
& \mu_{B S}= \begin{cases}0 & ; x \leq 35 \\
\frac{(x-35)}{(45-35)} & ; 35 \leq x \leq 45 \\
1 & ; x \geq 45\end{cases}
\end{aligned}
$$

\section{Keterangan:}

$\mathrm{C}=$ Cukup

$\mathrm{B}=$ Baik

BS = Baik Sekali 


\subsection{Domain Data Penilaian Dosen}

Domain untuk data kuesioner dosen adalah

$\begin{array}{ll}\text { Cukup } & =\left[\begin{array}{ll}0 & 25\end{array}\right] \\ \text { Baik } & =\left[\begin{array}{ll}20 & 40\end{array}\right] \\ \text { Baik Sekali } & =\left[\begin{array}{ll}35 & 50\end{array}\right]\end{array}$

\subsection{Rules}

Rules adalah aturan yang ditabulasikan sebagai kata-kata fuzzy, yakni:

$$
\begin{aligned}
& \mathrm{K}=\text { Kurang } \\
& \mathrm{C}=\text { Cukup } \\
& \mathrm{B}=\text { Baik }
\end{aligned}
$$

Aturan fungsi $f$

$$
\mathrm{f}=\{\mathrm{K}, \mathrm{C}, \mathrm{B}\}
$$

Tabel berikut menggambarkan rule (aturan fuzzy) berdasarkan hasil analisis yang penulis lakukan.

\begin{tabular}{|c|c|c|c|c|c|}
\hline \multirow{2}{*}{$\begin{array}{c}\text { Penilaian } \\
\text { Dosen (v) }\end{array}$} & \multicolumn{5}{|c|}{ Penilaian Mahasiswa (x) } \\
\cline { 2 - 7 } & KS & K & C & B & BS \\
\hline C & K & K & C & C & B \\
\hline B & K & C & C & B & B \\
\hline BS & C & C & B & B & B \\
\hline
\end{tabular}

\subsection{Desain Database}

Database yang digunakan untuk program testing ini terdiri dari 12 tabel. Yaitu 5 tabel master dan 7 tabel transaksi. Table-tabel masternya adalah tabel dosen, tabel mahasiswa, tabel himpunan, table variabel dan tabel kuisioner. Tabel variabel digunakan untuk menampung data variabel yang terdiri dari variabel dosen dan variabel mahasiswa. Tabel himpunan digunakan untuk menampung data record himpunan yang terdiri dari himpuan kurang sekali, kurang, cukup, baik, dan baik sekali yang merupakan himpunan dari variabel mahasiswa, himpunan cuku, kurang dan baik yang merupakan himpunan dari variabel dosen. Tabel fungsi keanggotaan digunakan untuk menampung data record fungsi keanggotaan yang terdiri dari varibel mahasiswa dengan:

1. Himpunan kurang sekali, maka nilai $\mathrm{X} 1=\mathrm{x} \leq \mathrm{a}, \mathrm{X} 2=\mathrm{x} \geq \mathrm{a}$ and $\mathrm{x} \leq \mathrm{c}, \mathrm{X} 3=\mathrm{x} \geq \mathrm{c}$ dengan hasil, $H 1=1, H 2=(c-x) /(c-a), H 3=0$.

2. Himpunan kurang, maka nilai $\mathrm{X} 1=\mathrm{x} \leq \mathrm{a}$ or $\mathrm{x} \geq \mathrm{c}, \mathrm{X} 2=\mathrm{x}>=\mathrm{a}$ and $\mathrm{x}<=\mathrm{b}, \mathrm{X} 3=\mathrm{x}>=$ $\mathrm{b}$ and $\mathrm{x}<=\mathrm{c}$, dengan hasil $\mathrm{H} 1=0, \mathrm{H} 2=(\mathrm{x}-\mathrm{a}) /(\mathrm{b}-\mathrm{a}), \mathrm{H} 3=1$. 
3. Himpunan cukup, maka nilai $\mathrm{X} 1=\mathrm{x}<=\mathrm{a}$ or $\mathrm{x}>=\mathrm{c}, \mathrm{X} 2=\mathrm{x}>=\mathrm{a}$ and $\mathrm{x}<=\mathrm{b}, \mathrm{X} 3=\mathrm{x}>=$ $\mathrm{b}$ and $\mathrm{x}<=\mathrm{c}$, dengan hasil $\mathrm{H} 1=0, \mathrm{H} 2=(\mathrm{x}-\mathrm{a}) /(\mathrm{b}-\mathrm{a}), \mathrm{H} 3=1$.

4. Himpunan baik, maka nilai $\mathrm{X} 1=\mathrm{x}<=\mathrm{a}$ or $\mathrm{x}>=\mathrm{c}, \mathrm{X} 2=\mathrm{x}>=\mathrm{a}$ and $\mathrm{x}<=\mathrm{b}, \mathrm{X} 3=\mathrm{x}>=\mathrm{b}$ and $\mathrm{x}<=\mathrm{c}$, dengan hasil, $\mathrm{H} 1=0, \mathrm{H} 2=(\mathrm{x}-\mathrm{a}) /(\mathrm{b}-\mathrm{a}), \mathrm{H} 3=(\mathrm{c}-\mathrm{x}) /(\mathrm{c}-\mathrm{b})$.

5. Himpunan baik sekali, maka nilai $\mathrm{X} 1=\mathrm{x}<=\mathrm{a}, \mathrm{X} 2=\mathrm{x}>=\mathrm{a}$ and $\mathrm{x}<=\mathrm{b}, \mathrm{X} 3=\mathrm{x}>=\mathrm{b}$, dengan hasil, $H 1=0, H 2=(x-a) /(b-a), H 3=1$.

6. Kemudian variabel dosen dengan himpunan cukup, maka nilai $\mathrm{X} 1=\mathrm{x}<=\mathrm{a}, \mathrm{X} 2=\mathrm{x}$ $>=\mathrm{a}$ and $\mathrm{x}<=\mathrm{c}, \mathrm{X} 3=\mathrm{x}>=\mathrm{c}$, dengan hasil, $\mathrm{H} 1=1, \mathrm{H} 2=(\mathrm{a}-\mathrm{x}) /(\mathrm{c}-\mathrm{a}), \mathrm{H} 3=0$.

7. Himpunan baik, maka nilai $\mathrm{X} 1=\mathrm{x}<=\mathrm{a}$ or $\mathrm{x}>=\mathrm{c}, \mathrm{X} 2=\mathrm{x}>=\mathrm{a}$ and $\mathrm{x}<=\mathrm{b}, \mathrm{X} 3=\mathrm{x}>=\mathrm{b}$ and $\mathrm{x}<=\mathrm{c}$, dengan hasil, $\mathrm{H} 1=0, \mathrm{H} 2=(\mathrm{x}-\mathrm{a}) /(\mathrm{b}-\mathrm{a}), \mathrm{H} 3=(\mathrm{c}-\mathrm{x}) /(\mathrm{c}-\mathrm{b})$,

Himpunan baik sekali, maka nilai $\mathrm{X} 1=\mathrm{x}<=\mathrm{a}, \mathrm{X} 2=\mathrm{x}>=\mathrm{a}$ and $\mathrm{x}<=\mathrm{c}, \mathrm{X} 3=\mathrm{x}>=\mathrm{c}$, dengan hasil $\mathrm{H} 1=0, \mathrm{H} 2=(\mathrm{x}-\mathrm{a}) /(\mathrm{c}-\mathrm{a}), \mathrm{H} 3=1$.

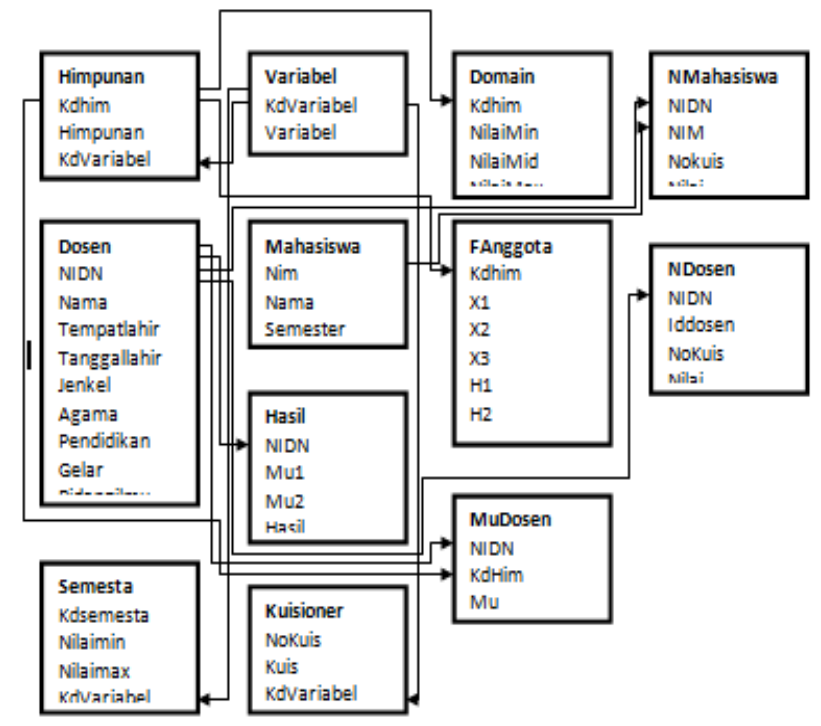

\section{Hasil percobaan:}

Hasil kuesioner yang diisi oleh mahasiswa dengan menggunakan metode Cronbach's Alpha untuk data training yang terdiri dari 60 data mahasiswa, sedangkan untuk keseluruhan data sebagai data testing penulis menggunakan sebanyak 1000 data mahasiswa. Data kuesioner yang diisi oleh dosen untuk data training yang terdiri dari 60 data dosen, sedangkan untuk keseluruhan data sebagai data testing penulis menggunakan sebanyak 70 data dosen.

\section{Hasil Training Data:}

Dalam pengujian data training yang terdiri dari 60 data mahasiswa dapat dilihat pada Tabel dibawah ini : 
Tabel 4.1. Signifikan dan Reliabilitas Statistik 60 data mahasiswa

\begin{tabular}{|r|l|r|}
\hline $\begin{array}{r}\text { Cronbach' } \\
\text { s Alpha }\end{array}$ & $\begin{array}{l}\text { Cronbach' } \\
\text { s Alpha } \\
\text { Based on } \\
\text { Standardi } \\
\text { zed Items }\end{array}$ & N of Items \\
\hline, 917 &, 918 & 5 \\
\hline
\end{tabular}

Tabel 4.2. Signifikan dan Reliabilitas Statistik 1000 data mahasiswa

\begin{tabular}{|r|r|r|}
\hline $\begin{array}{c}\text { Cronbach } \\
\text { 's Alpha }\end{array}$ & $\begin{array}{c}\text { Cronbach } \\
\text { 's Alpha } \\
\text { Based on } \\
\text { Standardi } \\
\text { zed Items }\end{array}$ & \multicolumn{2}{|c|}{$\begin{array}{c}\text { N of } \\
\text { Items }\end{array}$} \\
\hline, 924 &, 926 & 5 \\
\hline
\end{tabular}

Tabel 4.3 Signifikan dan Reliabilitas Statistik 60 data dosen

\begin{tabular}{|c|c|r|}
\hline & $\begin{array}{c}\text { Cronbach's } \\
\text { Alpha Based } \\
\text { on } \\
\text { Cronbach's } \\
\text { Alpha }\end{array}$ & $\begin{array}{c}\text { Standardized } \\
\text { Items }\end{array}$ \\
\hline N of \\
Items \\
\hline 923 &, 926 & 5 \\
\hline
\end{tabular}

Tabel 4.4 Signifikan dan Reliabilitas Statistik 70 data dosen

\begin{tabular}{|c|c|c|}
\hline $\begin{array}{c}\text { Cronbach's } \\
\text { Alpha }\end{array}$ & $\begin{array}{c}\text { Cronbach's } \\
\text { Alpha Based } \\
\text { on } \\
\text { Standardized } \\
\text { Items }\end{array}$ & $\mathrm{N}$ of Items \\
\hline, 927 & ,929 & 5 \\
\hline
\end{tabular}

[3]Cronbach's alpha diberikan survei untuk mengukur konsistensi internal. Menurut Mitchell dan Jolley (1999), Cronbach's alpha di atas 0,60 dapat diterima sebagai bukti reliabilitas internal. Survei didapatkan hasil koefisien Cronbach's alpha seperti yang dijelaskan dalam Tabel 4.1 sampai dengan Tabel $4.4>0.60$ artinya nilai-nilai untuk pengujian reliabilitas berasal dari skor-skor item angket yang valid. Dari hasil training dan testing dapat disimpulkan bahwa data yang penulis gunakan adalah valid dan dapat dipercaya. Dari perbedaan data training dan testing dapat dilihat sebagai berikut: 


\begin{tabular}{|l|c|c|}
\hline Variabel Data & $\begin{array}{l}\text { Cronbach's alpha } \\
\text { Data Training }\end{array}$ & $\begin{array}{l}\text { Cronbach's alpha } \\
\text { Data Testing }\end{array}$ \\
\hline Data 60 Mahasiswa & .917 & \\
\hline Data 1000 Mahasiswa & & .924 \\
\hline Data 60 Dosen & .923 & .927 \\
\hline Data 70 Dosen & & \\
\hline
\end{tabular}

\section{Hasil implementasi:}

Terlebih dahulu dimasukkan data2 master dari kedua variable, yaitu mahasiswa dan dosen. Dimulai dari data master variable, himpunan, semesta pembicaraan, dan domain. Setelah seluruh data master diinput, maka selanjutnya diinput data transaksi yang tampilannya sbb:

\section{Fungsi keanggotaan mahasiswa}

Form $\mu$ mahasiswa digunakan untuk mengolah data hasil nilai dari mahasiswa. Nilai yang diambil adalah nilai maksimal.

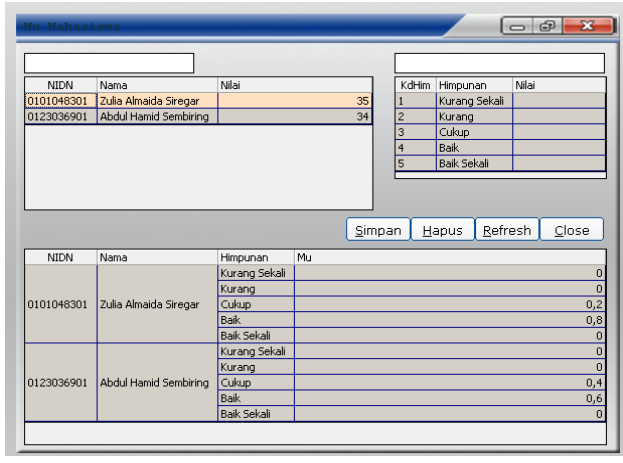

\section{Fungsi keanggotaan dosen:}

Form $\mu$ dosen digunakan untuk mengolah data hasil nilai dari dosen. Nilai yang diambil adalah nilai maksimal.

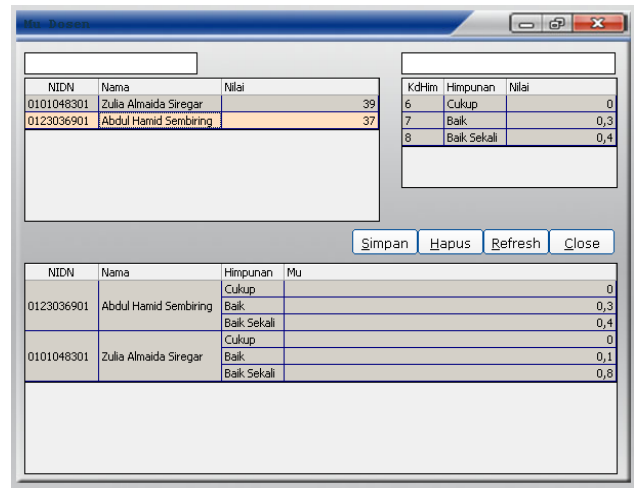




\section{Hasil rekomendasi:}

Form hasil rekomendasi akan memperlihatkan nilai dari kinerja dosen masing-masing beserta dengan kriterianya. Nilai kinerja dan kriteria diambil dari nilai $\mu$ dosen dan $\mu$ mahasiswa berdasarkan nilai minimal.

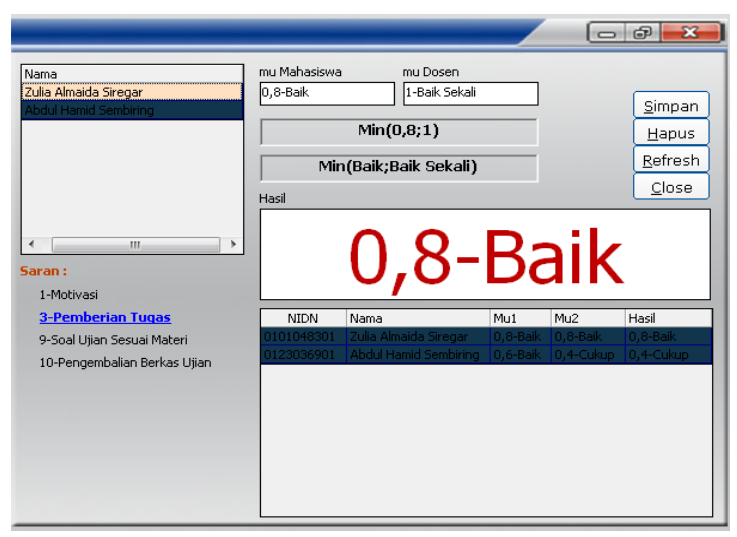

\section{KESIMPULAN:}

Perguruan Tinggi perlu mengadakan penilaian terhadap kinerja dosen. Khususnya AMIK Tunas Bangsa. Dengan adanya penilaian kinerja dosen, maka dengan sendirinya keberhasilan proses belajar mengajar akan berjalan sesuai dengan yang diinginkan. Yang perlu diperhatikan dalam penilaian ini adalah pengawasan dari pihak penilai/manajemen. Rekomendasi yang dihasilkan dari penelitian ini nantinya bisa dijadikan acuan untuk pengambilan keputusan pihak manajemen terhadap kebijakan yang akan diambil terhadap seorang dosen kedepannya.

\section{DAFTAR PUSTAKA}

[1] Kusumadewi, S. dan Purnomo, H., “Aplikasi Logika Fuzzy untuk system pendukung keputusan”, Andi Offset, Yogyakarta, 2010.

[2] Kusumadewi, S., "Fuzzy quantification theory I untuk analisis hubungan antara penilaian kinerja dosen oleh mahasiswa, kehadiran dosen, dan nilai kelulusan mahasiswa", Media Informatika, vol. 2, No. 1, 2010, pp. 1-10, 2004.

[3] Sundani, D., "Perangkat lunak SPSS sebagai alat untuk analisa hubungan kinerja dosen dengan keberhasilan belajar", Jurnal Informatika Komputer, vol.13, 2008.

[4] Wulandari, F., “Pembuatan sistem pendukung keputusan berbasis teori fuzzy untuk mengembangkan suatu produk baru", Jurnal Sain, Teknologi \& Industri, vol.2:62-66, 2005. 
[5] Dewi Novia Nursa., "Implementasi pangkalan data fuzzy model Tahani pada perekomendasian pembelian mobil", Skripsi Sarjana Sains. FMIPA Universitas Sumatera Utara, 2010.

[6] Poningsih, "Fuzzy Query Database untuk model umpan balik dosen", Jurnal IKTB, Jurnal Ilmiah informatika dan komputer, vol. 1, no. 1, pp 1-54, 2012.

[7] Poningsih, "Analisa Faktor pada Fuzzy Query Database", Jurnal IKTB, Jurnal Ilmiah informatika dan komputer, vol. 1, no. 2, pp 1-29, 2013. 